\title{
Increasing dose of methylprednisolone pulse therapy treats desquamative interstitial pneumonia in a child
}

\author{
K. Paul*, U. Klettke*, J. Moldenhauer*, K.M. Müller**, I. Kleinau*, K. Magdorf*, U. Wahn*
}

Increasing dose of methylprednisolone pulse therapy treats desquamative interstitial pneumonia in a child. K. Paul, U. Klettke, J. Moldenhauer, K.M. Müller, I. Kleinau, K. Magdorf, U. Wahn. C ERS Journals Ltd 1999.

ABSTRACT: A 10 yr old male with hypoxaemia, progressive infiltration on the chest radiograph and biopsy-proven desquamative interstitial pneumonia was treated with daily oral prednisolone for 6 months.

Intravenous methylprednisolone pulses were concomitantly administered in doses averaging $10 \mathrm{mg} \cdot \mathrm{kg}$ body weight ${ }^{-1}$ on three consecutive days every 4-6 weeks. After 6 months improvement could be noted and oral steroids were stopped, while pulse therapy continued. Three months later, when seven pulses had been administered, a relapse occurred and the clinical status deteriorated.

Instead of reinstating daily systemic steroids, the dose of methylprednisolone pulses was increased to $20 \mathrm{mg} \cdot \mathrm{kg}$ body weight ${ }^{-1} i$.v. given on three consecutive days and repeat pulses every 4 weeks. This was followed by continuous improvement. After 24 months corticosteroid pulses were terminated. Normal lung function, serum lactate dehydrogenase, blood gases upon exertion and regular development was achieved. During the course of treatment, the child has grown $10 \mathrm{~cm}$.

It is concluded that the effect of corticosteroid pulse therapy on interstitial lung disease in childhood is dose-dependent and that the dose can be adjusted to the effect observed.

Eur Respir J 1999; 14: 1429-1432.
*Krankenhaus Heckeshorn, Berlin, **Pathologisches Institut, Krankenhaus Bergmannsheil, University-Klinik Bochum, Germany.

Correspondence: K. Paul

Humboldt-University, Medical Center

Charité Children's Hospital

Dept of Pneumology and Immunology

Augustenburger Platz 1

13353 Berlin

Germany

Fax: 493045066983

Keywords: Desquamative interstitial pneumonia

dose adjustments

pulse therapy

Received: October 201998

Accepted after revision May 191999
Desquamative interstitial pneumonia (DIP) is a rare disease in childhood, with distinct features that make it distinguishable from other diffuse parenchymal lung disorders [1-10]. The origin is unknown. Although no standard treatment has been developed, daily oral corticosteroids, chloroquine and high dose intravenous corticosteroid pulses have been employed successfully. The authors report for the first time on a child where augmentation of the dose of corticosteroid pulse therapy led to a complete clinical remission and had a long-lasting effect that is sustained 2 yrs after cessation of therapy.

\section{Case history}

The child was born in 1983 with a gestational age of 30 weeks (weight $1,180 \mathrm{~g}$, length $37.5 \mathrm{~cm}$ ). Soon after birth retrolental fibroplasia was diagnosed with marked reduction of vision (right eye no vision, left eye 10\%). Apart from febrile seizures and a ventricular septal defect (VSD) with spontaneous closure no further abnormalities were reported until 1993, when he was presented to a hospital elsewhere because of reduced exercise tolerance. Clinically there were rales on the left lower lung with deep inspiration.

Radiologically, an alveolar infiltration in the right cardio-diaphragmatic angle and streaky infiltrates in both upper, lower and middle lung fields were described and interpreted as bilateral bronchopneumonia. A bronchoscopic examination yielded Escherichia coli and Strepto- coccus pneumoniae in the bronchial secretions. A perfusion scan demonstrated a combined perfusion and ventilation defect on the medial parts of the lungs. The boy was treated with erythromycin, did not improve adequately and was released from the hospital with an inhalation therapy with mucolytics and intermittent oxygen. Five months later he was readmitted with progression of radiological signs (fig. 1) and referred to the authors' hospital.The authors saw an almost $10 \mathrm{yr}$ old boy with a weight of 27 $\mathrm{kg}$ (below the 25th percentile), and a height of $132 \mathrm{~cm}$ (about 3rd percentile). He was dyspnoeic and cyanotic, his breath rate was above $40 \cdot \mathrm{min}^{-1}$, the heart beat frequency was $120 \cdot \mathrm{min}^{-1}$, and blood pressure $120 / 80 \mathrm{mmHg}$. On both lungs expiratory wheezing and rales could be heard, vital capacity (VC) was $<30 \%$ predicted. Arterial oxygen saturation $\left(\mathrm{Sa}, \mathrm{O}_{2}\right)$ at rest without complementary oxygen was $<80 \%$, partial pressure of carbon dioxide $\left(\mathrm{PCO}_{2}\right) 34.2 \mathrm{mmHg}$. With $3 \mathrm{~L}$ of complementary oxygen, $\mathrm{Sa}_{\mathrm{a}} \mathrm{O}_{2}$ rose to $89 \%$. Laboratory tests showed no signs of infection with viruses or bacteria, serum lactate dehydrogenase $(\mathrm{LDH})$ was increased $\left(550 \mathrm{IU} \cdot \mathrm{L}^{-1}\right)$.

A flexible fibreoptic bronchoscopy was inconclusive, the differential count of cellular components of the bronchoalveolar lavage (BAL) fluid from the middle lobe was normal. A computed tomography (CT) scan showed a patchy distribution of the alterations of the lung parenchyma, compatible with alveolar filling disease. Because of the patient's marked hypoxaemia, his poor response to oxygen therapy and the clinical suspicion of incipient 


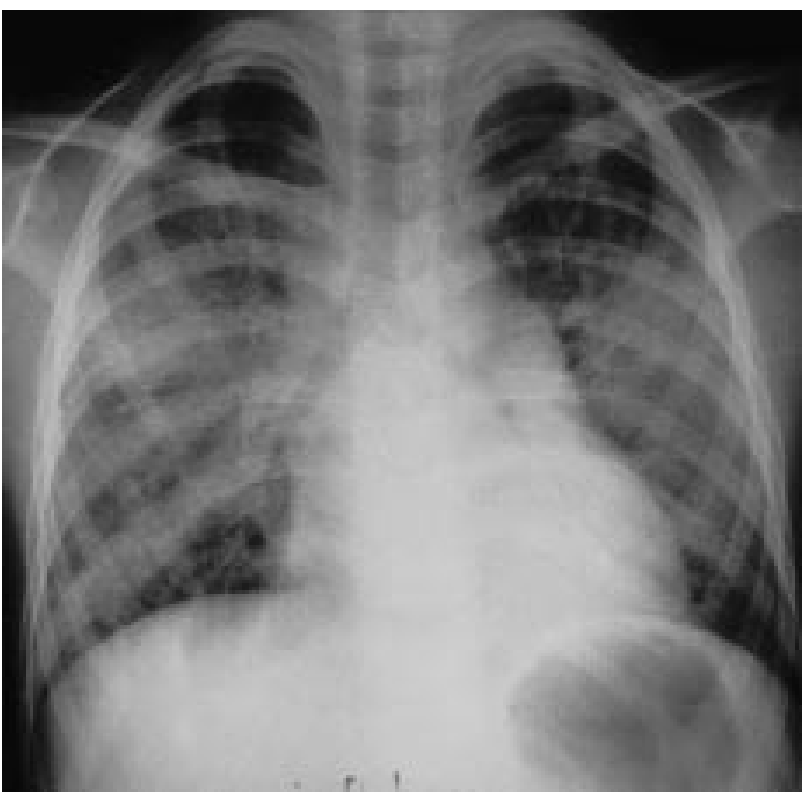

Fig. 1. - Radiological appearance at the first presentation of the child demonstrating accentuation of the bronchoalveolar markings at the basal parts of both lungs and diffuse alveolar opacification, more marked on the left side.

pulmonary hypertension an open lung biopsy was immediately performed conducted by video-assisted thoracoscopy. The histology (fig. 2) was graded as the typical picture of desquamative interstitial pneumonia with alveolar spaces filled with macrophages (CD63+ cells).

After the operation the boy was ventilated with $100 \%$ oxygen, systemic steroids were started (40 mg prednisolone.day ${ }^{-1}$ ) and he could be extubated 2 days later. In addition, the first methylprednisolone pulse therapy was administered the same week starting with $600 \mathrm{mg}$ on three consecutive days and continued at a dose of $10 \mathrm{mg} \cdot \mathrm{kg}$ body weight ${ }^{-1}$ (average $300 \mathrm{mg} \cdot$ day $^{-1}$ ) on three consecutive days every 4-6 weeks. The clinical course was monitored by oxygen saturation upon exertion, serum LDH, and lung function parameters (fig. 3). After clinical response daily oral steroids were reduced stepwise and tapered to $2.5 \mathrm{mg}$ until September 1994

By January 1995 a marked improvement in physical exercise tolerance had been achieved, while serum LDH was still high. VC had improved to $>50 \%$ predicted (fig. 3). Supplemental oxygen, which had been given continuously over $1 \mathrm{yr}$, had been withdrawn. A 12-min walk test at the patients "incited" own chosen speed without supplementary oxygen did not show $\mathrm{Sa}_{\mathrm{a}} \mathrm{O}_{2}$ deterioration.

When daily oral steroids were discontinued in January 1995, a decline of lung function parameters and decrease of oxygen saturation during the 12-min walk could be observed (fig. 3). There were two therapeutic alternatives: 1) to reinstate daily systemic steroids; or 2) to increase the dose of the pulse therapy. The decision was made to increase the dose of pulse therapy to $20 \mathrm{mg} \cdot \mathrm{kg}$ body weight $^{-1}$ and to avoid daily systemic corticosteroids. Soon after, the general clinical status of the boy and pulmonary function parameters improved gradually but steadily and infiltrations in thorax radiograph cleared completely. In October 1995 his VC was almost $80 \%$ predicted and his oxygen saturation stayed $>90 \%$ upon exercise. In June

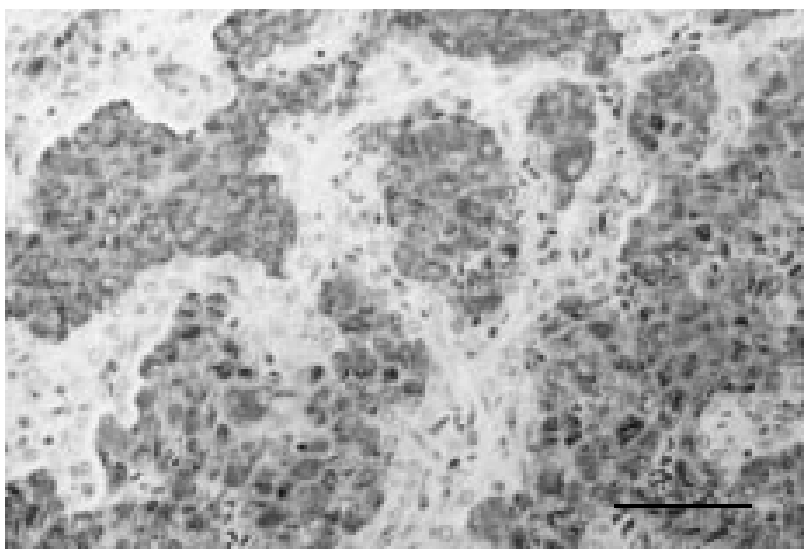

Fig. 2. - Alveoli filled with CD63 antibodies (Deko, Copenhagen, Denmark) staining alveolar macrophages typical for desquamative interstitial pneumonia. Internal scale bar $=100 \mu \mathrm{m}$.

1996, after almost 24-months of treatment, corticosteroids were stopped completely. There was no relapse during the following observation period of $>2$ yrs (fig. 3). There were only marginal side effects of steroid therapy as demonstrated by normal growth of $10 \mathrm{~cm}$ within the 2 yrs of treatment and catch-up growth after cessation of therapy. During therapy the boy had no cushingoid appearance but gained weight inadequately. After cessation of therapy weight normalized (fig. 3).

\section{Discussion}

DIP is a rare disease with distinct clinical features [6]. The name is derived from the early concept that the cells filling the alveolar spaces are type II pneumocytes [5]. It is now clear that these cells are not of alveolar origin but are macrophages. Histologically they can be stained with anti-CD63 antibodies (fig. 2). The aetiology of the disease is not clear. Clinically DIP bears some similarity to alveolar proteinosis. The radiological picture, the patchy distribution in $\mathrm{CT}$, the elevation of serum LDH, the rightleft shunt and a genetic background can be present in both diseases [7, 11]. A defect in macrophage activation has now been described in some forms of alveolar proteinosis [12]: a transition from DIP to alveolar proteinosis has been reported $[8,13]$. Although the aetiology of DIP is unclear, a defect of the macrophages, possibly by external injury on the basis of a genetic background, can be suspected. The disease has been reported in several members of a family, at all ages [2, 9, 14]. DIP has further been differentiated from usual interstitial pneumonia (UIP) which has a worse prognosis in older patients [3, 4, 15].

Different modes of treatment, most of which included steroids, have been reported [4, 14, 16-18]. The response to systemic steroids is usually good in older children, but there is considerable long-term toxicity, poor compliance with daily oral corticosteroids and relapses are frequently observed [8]. Recently, a series of case reports showed that pulse therapy has proved especially effective in DIP which was unresponsive to continuous systemic therapy in children [18]. The effect of high dose pulse therapy is attributed to nonreceptor dependent steroid activities [19, 20]. In addition, it has been discussed whether downregulation of steroid receptor sensitivity which can be 
a)

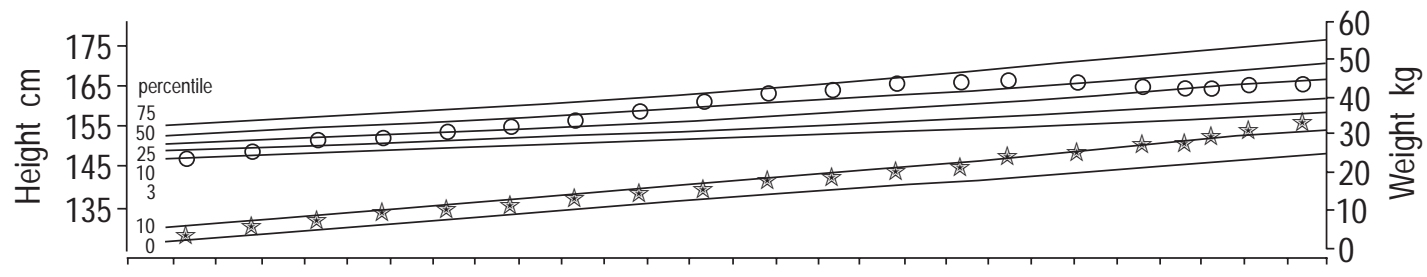

b)

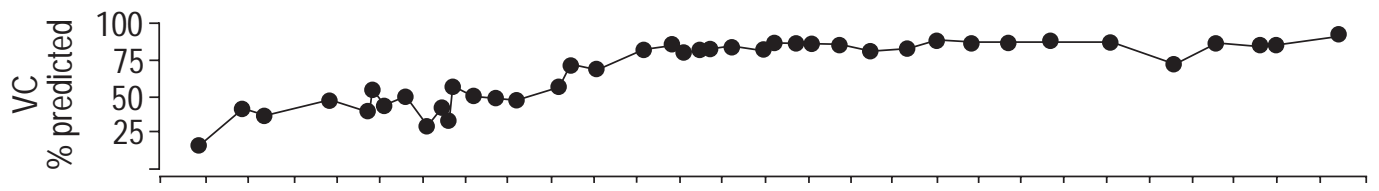

c)

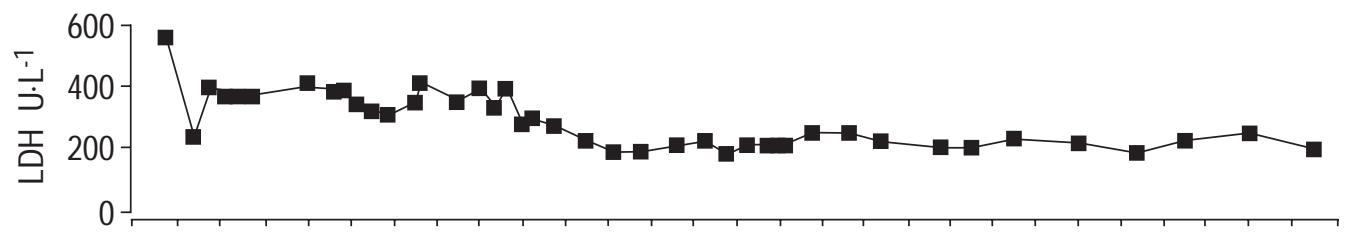

d)

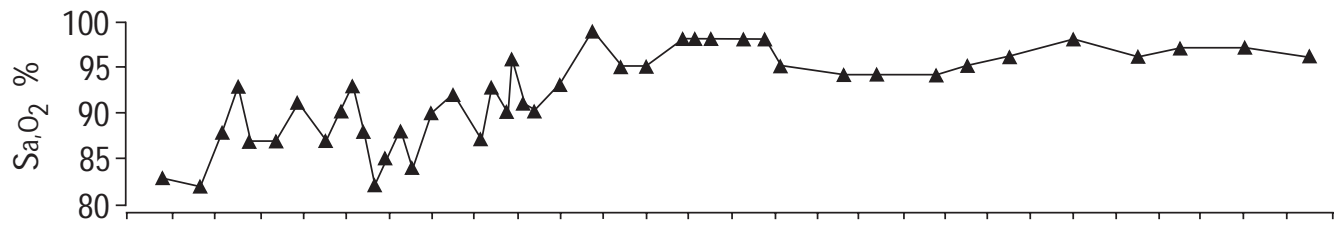

e)

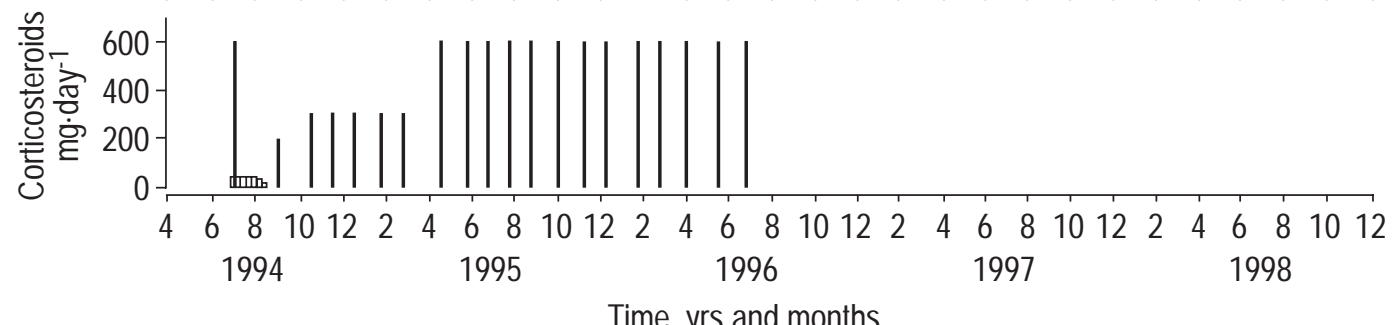

Fig. 3. - a) height (*; left-hand y-axis), weight ( $\bigcirc$; right-hand y-axis); b) vital capacity (VC); c) serum lactate dehydrogenase (LDH); d) oxygen saturation $\left(\mathrm{S}_{\mathrm{a}}, \mathrm{O}_{2}\right)$ at rest (on June, August 1994 and March 1995, because he was too ill to perform the test) and upon exertion during the course of treatment. The exercise was performed as 12-min walk test at the patient's chosen speed; and e) oral daily prednisolone ( $\square$ ) and IV methylprednisolone.

seen in daily treatment could be avoided by pulse therapy [21]. Steroid pulse therapy has been used in a number of inflammatory, especially autoimmune states, and has also proved effective in bronchiolitis obliterans organizing pneumonia (BOOP) in connection with graft versus host disease after allogeneic bone marrow transplantation in childhood [22]. This form of treatment can be especially favourable in children, since side effects on growth are minimized.

Although doses ranging $10-30 \mathrm{mg} \cdot \mathrm{kg}$ body weight ${ }^{-1}$ methylprednisolone have been suggested for pulse therapy in children, the decision is frequently empirical and a dosedependent effect has only been studied systematically in Blackfan-Diamond anaemia [23]. An effect of an increase in dose in DIP has never been reported in the literature before. Although the effect which is responsible for the successful treatment cannot be determined, the improvement after doubling the dose of the single pulse without further continuous systemic therapy suggests that the dose adjustment in pulse therapy contributed markedly to the favourable course. Methylprednisolone pulse therapy should therefore not only be considered as a valuable adjunct to treatment measurements in interstitial lung diseases, but the dose should be adjusted to the effect observed. Alternatives to a methylprednisolone treatment are chloroquine, which was the authors' second choice because of the retinopathy sometimes observed after this treatment and the visual impairment that the child had already suffered from his retrolental fibroplasia [16, 17, 24].

It is concluded that steroid pulse therapy in interstitial lung diseases in children should be evaluated systematically with different dose ranges in a multicentre approach.

Acknowledgements. The authors thank J. Waldschmidt for performing the lung biopsy.

\section{References}

1. Laraya-Cuasay LR. Desquamative interstitial pneumonitis. In: Laraya-Cuasay LR, Hughes WT. Interstitial Lung Diseases in Children Volume 3. Boca Raton, FL, USA, CRC Press, 1988; pp. 130-133.

2. Bonanni PP, Frymoyer JW, Jacox RF. A family study of idiopathic pulmonary fibrosis: a possible dysproteinemic and genetically determined disease. Am J Med 1965; 39: 411-421. 
3. Sharief N, Crawford OF, Dinwiddie R. Fibrosing alveolitis and desquamative interstitial pneumonia. Pediatr Pulmonol 1994; 17: 359-365.

4. Carrington CB, Gaensler EA, Coutu RE, Fitzgerald M, Gupta RG. Natural history and treated course of usual and desquamative interstitial pneumonia. N Engl J Med 1978; 298: 801-809.

5. Farrell PM, Gilbert EF, Zimmermann JJ, Warner TF, Saari TN. Familial lung disease associated with proliferation and desquamation of type II pneumonocytes. Am J Dis Child 1986; 140: 262-266.

6. Liebow AA, Steer A, Billingsley JG. Desquamative interstitial pneumonia. Am J Med 1965; 39: 369-404.

7. Scully RE, Mark EJ, McNeely BU. Case 9-1983 - Case records of the Massachusetts General Hospital. $N$ Engl $J$ Med 1983; 308: 511-519.

8. Scully RE, Mark EJ, McNeely WF, McNeely BU. Case 49-1993 - Case records of the Massachusetts General Hospital. N Engl J Med 1993; 329: 1797-1805.

9. Tal A, Maor E, Bar-Ziv J, Gorodischer R. Fatal desquamative intersitial pneumonia in three infants siblings. J Pediatr 1984; 104: 873-876.

10. Brugman S, Wilson H, Fan L. Interstitial lung disease. In: Loughlin GM, Eigen H, eds. Respiratory Disease in Children. Diagnosis and Management. Baltimore, MD, USA, Williams \& Wilkins, 1994; pp. 395-410.

11. Feigin DS, Friedmann PJ. Chest radiography in desquamative interstitial pneumonitis: a review of 37 patients. Am J Roentgenol 1980; 134: 91-99.

12. Seymor JF, Dunn AR, Vincent JM, Presneill JJ, Pain MC. Efficacy of granulocyte macrophage colony stimulating factor in acquired alveolar proteinosis. $N$ Engl J Med 1996; 335: 1924-1925.

13. Bhagwat AG, Wentworth P, Conen PE. Observations on the relationship of desquamative interstitial pneumonia and pulmonary alveolar proteinosis in childhood. A pathologic and experimental study. Chest 1970; 58: 326-332.

14. Balasubramanyan N, Murphy A, O'Sullivan J, O'Connell EJ. Familial interstitial lung disease in children: response to chloroquine treatment in one sibling with desquamative interstitial pneumonitis. Pediatr Pulmonol 1997; 23: 5561.

15. Hartmann TE, Primack SL, Kang KY, et al. Disease progression in usual interstitial pneumonia compared with desquamative intersititial pneumonia. Assessment with serial CT. Chest 1996; 110: 378-382.

16. Avital A, Godfrey S, Maayan C, Diamant Y, Springer C. Chloroquine treatment of interstitial lung disease in children. Pediatr Pulmonol 1994; 18: 356-360.

17. Kerem E, Bentur L, England S, et al. Sequential pulmonary function measurements during treatment of infantile chronic interstitial pneumonitis. J Pediatr 1990; 116: 61-67.

18. Osika E, Muller MH, Boccon-Gibod L, et al. Idiopathic pulmonary fibrosis in infants. Pediatr Pulmonol 1997; 23: 49-54.

19. Barnes PJ, Adcock I. Anti-inflammatory actions of steroids: molecular mechanisms. Trends Pharmakoi Science 1993; 14: 436-441.

20. Boumpas DT, Chrousors CP, Wilder RL, Cupps TR, Balow JE. Glucocorticoid therapy for immune-mediated diseases. Basic and clinical correlates. Ann Intern Med 1993; 119: 1198-1205.

21. Desmarquest P, Tamalet A, Fauroux B, et al. Chronic interstitial lung disease in children: response to high-dose intravenous methylprednisolone pulses. Pediatr Pulmonol 1998; 26: 332-338.

22. Kleinau I, Perez-Canto A, Schmid HJ, et al. Case report. Bronchiolitis obliterans organizing pneumonia and chronic graft-versus-host disease in a child after allogeneic bone marrow transplantation. Bone Marrow Transplantation 1997; 19: 841-844.

23. Bernini JC, Carrillo JM, Buchanan GR. High-dose intravenous methylprednisolone therapy for patients with Diamond-Blachfan anemia refractory to conventional doses of prednisone. J Pediatr 1995; 127: 654-659.

24. Easterbrook M. Ocular effects and safety of antimalarial agents. Am J Med 1988; 85: 23-29. 